\title{
Correspondências entre Joachim Le Breton e a corte portuguesa na Europa. nascimento da Missão Artística de 1816
}

\section{Elaine Dias ${ }^{1}$}

RESUMO: Uma série de documentos conservados no Arquivo Nacional da Torre do Tombo, em Lisboa, oferece-nos ainda instrumentos significativos para a compreensão da origem da Missão Artística de 1816. Embora alguns historiadores brasileiros tenham já explorado intensamente este campo, dentre os quais as preciosas publicações de Afonso d'Escragnolle Taunay, Mário Barata e Mário Pedrosa - destacando-se também os escritos de Jean-Baptiste Debret -, convém buscar novas luzes para entender a concepção do projeto de ensino artístico e industrial, ainda na Europa, pelas mãos de Joachim Le Breton. Como surgiu o projeto da Missão? Este artigo tem como objetivo a análise de algumas correspondências conservadas na Torre do Tombo, trocadas entre Le Breton e os diplomatas portugueses em 1815, ainda em Paris, visando à recuperação dos primeiros passos desta história.

PalAVRAS-CHAVE: Missao Artística. Francesa. Joachim Le Breton. Ensino artístico. Jean-Baptiste. Debret.

ABSTRACT: A series of documents kept at the National Archive of Tombo Tower in Lisbon offers us important tools to understand the origin of the 1816 Artistic Mission. Although some Brazilian historians have already explored this field extensively - including Afonso d'Escragnolle Taunay, Mário Barata and Mário Pedrosa in their invaluable publications, not to mention Jean-Baptiste Debret in his writings - it is important to shed new light on this subject so that we may understand how the project of art and industrial education was conceived in Europe by Joachim Le Breton. How did the Mission's project come about? This paper proposes to review certain letters kept at the Tombo Tower and exchanged between Portuguese diplomats and Le Breton in 1815 , while the latter was still in Paris, for the ultimate purpose of retracing the first steps of this story. KEYWORDS: French Artistic Mission. Joachim Le Breton. Arts teaching. Jean-Baptiste Debret.
1. Doutora em História (UNICAMP), Bolsista Fapesp de Pós-Doutoramento em Fundamentos da Arquitetura e do Urbanismo (FAU-USP). 
2. Debret (1975).

3. Duque-Estrada (1995).

4. Rios Filho (1942)

5.Taunay (1957)

6. Barata (1959). Neste mesmo ano, Barata publicou em Paris um artigo que tratava da mesma temática: Lebreton et l'organisation d'une doublé école des Beaux-Arts et des Arts Métiers au Brésil en 1816. A propos de la mission artistique française de 1816 (BARATA, 1959).
Artistas, críticos de arte e historiadores brasileiros há muito se debruçam sobre a origem e o desenvolvimento da chamada Missão Artística Francesa de 1816. Baseando-se em uma série de decretos promulgados no Brasil neste período, nos relatos de viajantes e nos documentos que engendram a história da Academia Imperial de Belas Artes, alguns estudiosos analisaram a trama que compõe esta passagem, fundamental ao entendimento da história da arte brasileira do século XIX.

Os escritos do pintor de história Jean-Baptiste Debret, presentes em sua obra Voyage pittoresque et historique au Brésil, publicada em três volumes em Paris entre 1834 e 1839, constitui uma das primeiras fontes que contribuíram para a abordagem da questão. Debret, membro do projeto de ensino criado pela Missão como pintor de história, fora o primeiro a tratar deste tema no terceiro volume de sua obra². Ali, relata o contexto vivido pelos artistas franceses no Rio de Janeiro, descrevendo as questões burocráticas, os entraves políticos, assim como as querelas entre artistas franceses e portugueses para a fundação da Academia de Belas Artes, inaugurada em 1826, dez anos depois da concepção de seu projeto inicial como Escola Real de Ciências, Artes e Ofícios.

Ainda no terreno historiográfico e literário do século XIX, o crítico de arte Luiz Gonzaga-Duque Estrada, em sua obra Arte brasileira ${ }^{3}$, sob a alcunha de Colônia Le Breton, discorrera a respeito da chegada dos franceses ao Rio de Janeiro para a fundação de tal Escola, projeto "concebido" pelo príncipe regente D. João VI. Na segunda parte do segundo capítulo, denominado Manifestações, Duque Estrada analisa os primeiros anos vividos pelos franceses Jean-Baptiste Debret e Nicolas-Antoine Taunay no Rio de Janeiro, ambos membros do projeto chefiado por Joachim Le Breton, e suas relações com os artistas portugueses Henrique da Silva e Simplício de Sá, nomeados professores da escola que então se organizava. Duque Estrada tece brevemente algumas considerações sobre a fundação da instituição, atendo-se de forma mais acurada à análise das obras realizadas por estes pintores naquele período.

Anos mais tarde, o historiador Adolfo Morales de los Rios Filho tratou igualmente desta temática, partindo também dos escritos de Debret, de Duque Estrada e de outras fontes documentais, em uma detalhada análise histórica do ensino artístico entre os anos de 1816 e 18894. Pouco tempo depois, Afonso d'Escragnolle Taunay abordou o tema de modo sistemático em sua obra A missão artística de 18165, publicada em 1957. Seus escritos tornar-se-iam referência fundamental ao assunto, não só pelo tratamento dado a este período específico da arte brasileira, mas por analisar individualmente a trajetória de cada um de seus participantes.

Entre outros historiadores, convém destacar o precioso conjunto de artigos escritos pelo professor Mário Barata, que, a partir de referências documentais encontradas nos arquivos brasileiros, igualmente abraçou o tema. Entre seus escritos, temos a tradução do plano de ensino elaborado por Le Breton em 1816, em artigo publicado na Revista do Patrimônio Histórico e Artístico Nacional, em 1959'. O original escrito por Le Breton, em francês, está conservado no Arquivo Histórico do Palácio do Itamaraty, no Rio de Janeiro. Barata recuperou 
dados importantes para a compreensão do projeto didático que originou a instituição acadêmica de Artes no Brasil, levando ao alcance do público o meticuloso plano de Le Breton, proposto em duas cartas dirigidas ao conde da Barca, em 1816, quando Le Breton já estava em território americano.

Todas estas referências fundamentais ao entendimento da questão são unânimes quanto às origens da Missão Artística e à oficialidade da chegada dos artistas ao Brasil. Existem, no entanto, dois trabalhos que deram um passo adiante nesta história, oferecendo contribuições documentais que tentam desvendar o dilema da chegada dos franceses. O primeiro é a obra realizada por Afonso Taunay, acima citada. Contemporâneo a ele, há o trabalho feito por Mário Pedrosa, em seu precioso texło sobre os obstáculos políticos que enredaram a Missão Francesa no Brasil?. Foi primeiro Taunay aquele a abordar, ainda que brevemente, os documentos que trataremos neste artigo. Ressalta a importância da comunicação entre Le Breton, ainda em Paris, e os agentes portugueses, considerando a tese de que a idéia da Missão teria, sim, partido do francês Le Breton. No entanto, à medida que esmiúça a questão, chega à conclusão de que a corte portuguesa teve um papel primordial na vinda dos franceses, ainda que a idéia tenha partido de Le Breton. D. João VI teria participado, mesmo que indiretamente, da criação do projeto de ensino, uma vez que os franceses chegaram aqui protegidos pela corte portuguesa. $\bigcirc$ apoio do conde da Barca, para Afonso Taunay, seria o voto de Minerva para o fechamento de uma questão que, a nosso ver, permanece nebulosa.

Mário Pedrosa recupera os documentos já utilizados por Taunay em sua publicação de 1957. A parte relativa aos primeiros passos da Missão havia sido anteriormente publicada no Jornal do Comércio, em 1923, pelo próprio Taunay, escritos que foram posteriormente publicados na obra sobre a Missão, recuperados por Pedrosa, enfatizando a questão. Ali, Pedrosa cita a documentação portuguesa, nota a importância de Le Breton na criação do projeto e na vinda do grupo, desvinculando-o de qualquer convite realizado pela corte, colocando-se em divergência com Taunay. A análise de Pedrosa é, desta maneira, a segunda abordagem fundamental ao entendimento de nossa história, depois de Taunay. Além de mostrar os primeiros passos ainda em Paris para a vinda dos franceses, recuperando os escritos de Taunay, Pedrosa vai adiante em sua interpretação, analisando também os documentos presentes nos acervos brasileiros que relatam os primeiros anos de Le Breton no Brasil. Conta-nos, a partir da fonte primária, o grande entrevero diplomático ocorrido, já no Rio de Janeiro, entre Le Breton e o general francês Jean-Baptiste Maler, diplomata da corte portuguesa e representante da Restauração francesa no Brasil. O texto de Pedrosa fornece elementos importantes para o entendimento das relações conflituosas estabelecidas entre Portugal, Brasil e França nos primeiros anos da Missão Artística.

Os dois autores, Taunay e Pedrosa, deram contribuições preciosas para um primeiro questionamento acerca da história da chegada dos franceses no Brasil. Depois deles, convém aqui ressaltar os trabalhos de Rodrigo Naves ${ }^{8}$. Este último recupera estes interessantes estudos e propõe uma interpretação
7. O texto de Pedrosa foi originalmente concebido para o concurso da cadeira de História do Colégio D. Pedro II. Ele pode ser consultado na publicação organizada por Otília Arantes (PEDROSA, 1998).

8. Naves (1996). 
9. O termo refere-se ao artesanato ligado ao desenvolvimento industrial. Também utilizam o termo 'Artes Industriais'

10. Sobre o papel desempenhado por Humboldt no continente americano, ver o interessante catálogo da Exposição Ale jandro de Humboldt. Una Nueva Vision del Mundo, 2003

11. A École Gratuite du Dessin foi fundada em Paris em 1763 e tornou-se École Royale Gratuite de Dessin de Paris a partir de 1766. Jean-Jacques $\mathrm{Ba}$ chelier, pintor de flores e animais, fundador da Escola, fora o responsáve por seu aprimoramento no nível dos Ofícios, criando inclusive o projeto de subscrição que a financiou durante muitos anos. Le Breton relata experiência de Bachelier com as subscrições em seu plano de ensino enviado ao conde da Barca em 1816. Esse plano está contido em duas cartas datadas de 12 de junho e 9 de julho de 1816, hoje conservadas no Arquivo Histórico do Palácio do Itamaraty no Rio de Janei ro. Sobre a École Royale Gratuite du Dessin de Paris ver MANTZ (1865) e LEBEN (2004).

12. Jouin (1892) particular à produção de Jean-Baptiste Debret no Brasil, estabelecendo uma relação entre sua formação neoclássica e sua produção nos trópicos. Passemos, então, aos primeiros passos desta história.

Primeiros passos

Teria partido do marquês de Marialva - ministro das Relações Exteriores de Portugal em Paris, representando o príncipe D. João VI, então com sua corte portuguesa em terras luso-brasileiras - o convite para a realização de um projeto de ensino artístico no Rio de Janeiro. Marialva, provavelmente influenciado pelo iluminado ministro conde da Barca e pelos relatos do engenheiro e naturalista Alexander von Humboldt, teria sido o articulador da proposta e posterior portavoz do príncipe D. João nesta empreitada. Antes desta etapa, porém, cabia primeiramente a Marialva convencer D. João acerca das vantagens do projeto de ensino. Tinha como exemplo os interessantes relatos de Humboldt sobre o desenvolvimento americano a partir da difusão dos Ofícios na cultura hispanoamericana da América Central, presentes em seu livro Essai politique sur le royaume de la nouvelle Espagne, publicado em Paris em 1811 . A Academia de los Nobles Artes, fundada no México em 1783, e descrita por Humboldt em sua obra, constituía um bem sucedido projeto de desenvolvimento industrial e artístico daquela região, agora institucionalizado e fortemente centralizado nos Ofícios (HUMBOLDT, 181 1). Por outro lado, o conde da Barca, ministro influente junto a D. João VI, seria, por sua vez, o grande apoiador do projeto em terras brasileiras, dado seu interesse pelo aprimoramento da indústria e das artes, fundamentais ao progresso das terras portuguesas no continente americano, a exemplo do que ocorria na América Espanhola. Marialva, Barca e Humboldt seriam, portanto, figuras centrais na criação e composição do projeto de ensino artístico, cujo fator principal era o desenvolvimento dos Ofícios.

Marialva e Barca compunham os interesses diplomáticos portugueses, respectivamente, na Europa e no Brasil. Humboldt, como correspondente estrangeiro do Institut de France e figura de grande destaque no âmbito da política européia e das Artes $^{10}$, teria indicado o nome de Le Breton como possível articulador de um programa didático no Brasil, dado seu interesse por projetos destinados aos Ofícios da França. Le Breton havia sido subscritor da Ecole Royale du Dessin, de Bachelier"1, em Paris, desde 1788, além de presidir seu Conselho de Administração desde 1801, adquirindo assim uma certa experiência no desenvolvimento de projetos artísticos no âmbito dos Ofícios. Vale lembrar que Le Breton acumulava igualmente a função de administrador das Obras de Arte no Musée du Louvre desde 1798, convertendo-se em colaborador de Vivant Denon na organização das coleções, em 1802'12. Ao mesmo tempo, Humboldt testemunhava sua fragilidade dentro do sistema político francês (em 1815) e, conseqüentemente, sua vulnerabilidade na instituição acadêmica, dado o seu envolvimento nas questões administrativas e políticas acerca da devolução dos 
objetos de arte adquiridos pela França nas guerras napoleônicas, conforme veremos adiante. Seria, portanto, um nome excelente para levar a cabo o projeto de ensino supostamente pedido pelos ministros portugueses, em nome do príncipe D. João VI. Acerca da relação entre o marquês de Marialva e Humboldt, diz Debret em sua obra:

Ministro plenipotenciário junto à corte de França em Paris, aí organizou um círculo íntimo de homens extremamente notáveis pelos seus conhecimentos e cultura. Entre estes se encontrava o Barão de Humboldt, um dos membros do Instituto de França, que, em 1815, Ihe inspiraram o desejo de fundar no Rio de Janeiro uma academia real de belas artes. Daí nossa expedição artística dirigida pelo senhor Lebreton, então secretário perpétuo da classe de belas artes do Instituto de França ${ }^{13}$.

Segundo Debret, o círculo de amizade e a influência de Humboldt teriam, portanto, despertado o interesse do marquês de Marialva para a criação de uma escola de Artes e Ofícios no Brasil. A citação a Humboldt é importante, e torna quase convincente a hipótese de que os projetos da Missão teriam partido do Brasil.

Vale a pena retomar esta questão e esmiuçar alguns documentos conservados no Arquivo Nacional da Torre do Tombo ${ }^{14}$, em Lisboa, os quais colocam em dúvida as palavras de Debret, reforçam as teses anteriores de Taunay e Pedrosa, e jogam novas luzes não só sobre as origens da formação do grupo, ainda em Paris, mas também sobre a gênese do projeto e o plano que seria conduzido por Le Breton no Brasil.

\section{As Correspondências}

Os ofícios de número 21,22 e $30^{15}$ referem-se a correspondências e outros documentos trocados entre os representantes da corte portuguesa em Paris - Francisco José Maria de Brito, o cavaleiro de Brito, e o marquês de Aguiar - e o reinado português estabelecido no Rio de Janeiro. Tais ofícios demonstram os primeiros contatos realizados entre Le Breton e a corte portuguesa na França. Naquele de $n^{\circ} 22$, os representantes da corte relatam:

No meu oficio no 17 tive a honra de comunicar a V. Ex que Mr. Lebreton, Secretario Perpetuo da Quarta Classe do Instituto me falara assim como ao Márquez Estribeiro Mor da emigração de artistas franceses para o Estado do Bresil, e que alguns desejavao e necessitavao de ajudas de custo, ao que the respondera, não estar para isso autorizado, mas que me cumpria das partes a V. Excia, esperar as Reais Ordens a este respeito. Não podendo então mandar com aquele oficio a Nota que Mr. Lebreton me prometera sobre os indivíduos que se propunham passar a este continente, tenho agora a honra de a remeter a $\mathrm{V}$. Excia.

Ao que parece, os ofícios de no 21 e 22 foram enviados juntos ao Reino, pois é no primeiro que se encontra a carta dirigida a Brito e Aguiar, assinada por Le Breton e datada de 3 de outubro de 1815. Nesta carta, Le
13. Debret (1975,p. 246).

14.As cópias dos ofícios da corte portuguesa e as correspondências entre o marquês de Aguiar, Francisco José Maria de Brito, e Joachim Le Breton foram gentilmente cedidas pelo historiador Antonio Luiz d'Araújo, que esteve em Lisboa $\mathrm{e}$ recuperou diversos documentos para sua pesquisa sobre arte colonial no Brasil.

15. Os textos estão transcritos diretamente do manuscrito, em português do período e também em francês, conservando-se a grafia original. Aqueles em francês foram traduzidos livremente pelo autor. 
16. "Uma vez estabelecida esta exclusão (isto é, retirada a ameaça da revolução), eu gostaria de enviar ao Brasil talentos práticos que aí propagassem a in dústria. Esta classe de homens é a mais fácil de se governar; ela está muito bem em todos os lugares onde ela prospera.

É necessário ao Brasil o crescimento da indústria, visto que os Estados que o rodeiam o adquirem a cada dia e tomarão um crescimento muito grande (distanciamento?); É o acaso, de alguma maneira, que conduz os homens de um mundo ao outro, e quando a imigração é considerável, nem a sabedoria dos Governos consegue dirigir este mínimo acaso; acontece como nos Estados Unidos, onde a amálgama não se dá, ou se dá de forma prejudicial. O Brasil não está tomado pelas ações políticas ou religiosas. O Governo estabelece, com grande maestria um bom sistema de colonização.Aquilo que o Duque de Richelieu fez na Criméia, para o favorecimento da Rússia, pode ter muito mais sucesso no Brasil: mas para não antecipar nada sobre os desenvolvimentos que seriam, talvez, generosos demais, eu chego ao ponto de vista específico que me interessa em primeiro lugar, qual seja o de realizar uma escolha limitada de homens dotados de conhecimentos ou de talentos práticos. Esta primeira colônia seria um ímã que mais tarde atrairia seus análogos.

Pode-se escolher na França, dentro de um grande espaço, desde as mais elevadas ciências até os ofícios, por exemplo, engenheiros de artilharia, de pontes, e pavimentos de construção naval, de minas, muitos estão sem ocupação, sem esperança de progressos eles es-
Breton apresenta sua intenção de organizar um projeto voltado aos Ofícios, sob a proteção da corte portuguesa. Inicia sua carta relatando o início, naquele mesmo ano, de um movimento de emigração de franceses para os Estados Unidos, para o Novo Reino dos Países Baixos e para a Alemanha, ressaltando, em seguida, as dificuldades de emigração para os países americanos de colonização espanhola, em conseqüência das "possessões" e "agitações" que conturbaram esses países. Pensando encontrar no novo reino português na América uma possibilidade de desenvolvimento, num país repleto de vantagens coloniais e pouco cotejado por esse movimento imigratório, Le Breton sugere, a exemplo do que aconteceu no México e claramente sob a influência de Humboldt, a criação de um projeto que promova a indústria e as artes no Brasil, formado por artistas franceses emigrados. Enfatiza ainda a ausência de quaisquer pretensões revolucionárias em seus propósitos e diz:

Cette exclusion une fois établie, je voudrais diriger sur le Brésil des talens pratiques qui y propageaient l'industrie. Cette classe d'hommes est la plus facile a gouverner; elle se trouve bien partout où elle prospère.[...]

Il faut au Brésil un accroissement d'industrie puisque les Étałs qui l'environnent en acquierent chaque jour et en prendont un très grand: C'est en quelque sorte le hasard qui promène les hommes d'un monde à l'autre, et quand l'émigration est considerable, ni la sagesse des Gouvernemens ne dirige pas ce peu du hasard, il arrive comme aux États-Unis quel'amalgamme ne se fait point, ou se fait mal. Le Brésil il n'est point envahi par les actes politiques, ou réligieuses: le Gouvernement y est maître d'y établir un bon systeme de colonisation. Ce que le Duc de Richilieu a fait en Crimée pour l'avantage de la Russie peut avoir bien plus de succès au Brésil: mais pour ne point anteciper sur les developemens qui seraient peut-être trop généraux je viens au point de vue particulier qui m'interesse d'avantage, celui de faire un choix limité d'homme doués de connaissances ou de talens pratique. Cette première colonie serait un aimant qui attirerait plus tard ses analogues.

On peut choisir en France dans une assez grand latitude depuis les hautes sciences jusqu'aux métiers, par exemple, des officier de génie, d'artillerie, des ponts et chaussées de constructions navale, des mines, beaucoup vont se trouver sans occupation, sans esperance d'avancement ils seront libres et l'on ne manquerait point au Gouvernement Français en les employant ${ }^{16}$.

Le Breton vê uma grande possibilidade de desenvolvimento dos Ofícios no Brasil, visto ser um país bem colonizado. Dadas as dificuldades políticas e sociais do continente europeu, muitos artesãos ou oficiais mais especializados poderiam ser aproveitados nesse sentido, na esperança de um progresso que se perdia na França. Mais adiante, cita aqueles que estariam iá disponíveis para o serviço, entre os quais um diretor de jardins, de Versailles, Trianon e St.Cloud, que iá passara um período nos Estados Unidos. Era o cavaleiro de St. Louis ou Mr.Villesuras Lelieur. E o outro, mais conhecido entre nós, seria um construtor de moinhos e usinas de água, que iria ao México e ao Peru por indicação do governo espanhol, cujo nome era "Ovide".

Já no âmbito das Belas Artes, Le Breton considerava que um ou dois pintores, escultores e arquitetos, um gravador e um desenhista de instrumentos seriam suficientes para formar a parte do programa de desenvolvimento "industrial". Este projeto não seria tão "suntuoso" e "dispendioso" quanto aquele 
realizado na Academia de los Nobles Artes pelo governo espanhol no México, conforme descrevera Humboldt em sua obra ${ }^{17}$. Em sua carta, Le Breton relata a Brito que já tem à sua disposição um pintor, um escultor, um arquiteto e um bom gravador. No que se refere à pintura e à escultura, trata-se de integrantes da "Família Taunay", composta de pai, mãe e cinco filhos, todos dispostos a partir de Paris para o Brasil ou para qualquer outro país que thes garantisse um futuro melhor. Le Breton faz os elogios à "Família Taunay", considerando que seus membros seriam de grande proveito para o Brasil, ao mesmo tempo em que essa encontraria a segurança que pretendia a partir dos frutos de seus próprios trabalhos. De todos os citados nominalmente por Le Breton nesse documento, tanto no que se refere aos Ofícios como às Belas Artes, somente François Ovide e a "Família Taunay" partem efetivamente para o Brasil.

A carta de Le Breton data de 3 de outubro de 1815. Segundo alguns ofícios posteriores, Le Breton teria enviado a proposta em 2 de setembro de 1815 , citando o projeto de indústria e os nomes dos possíveis componentes. Os ministros, no entanto, como bem relata o ofício posterior, de 9 de dezembro de 1815 (bem como o anterior, de 9 de outubro), não teriam nenhuma instrução ou ordem da corte que pudesse responder às suas pretensões ou direcionar a proposta da viagem. Parece-nos estranho que, sendo o convite dirigido a Le Breton pela corte portuguesa, não haja nenhuma instrução aos diplomatas em Paris acerca do assunto. $\bigcirc$ primeiro ofício em que a idéia aparece é o de $n$. 17 (apenas citado por Brito), certamente de setembro de 1815, e que não está presente na documentação aqui analisada. No entanto, nesse ofício de n.21, Brito parece repetir as idéias presentes no anterior, de n. 17, que contém as diretrizes do projeto de Le Breton.

A partir da idéia do projeto oferecido à corte através dos ofícios de outubro, novembro e dezembro de 1815, é possível avançar na questão. Le Breton envia, em 3 de outubro, uma nota ou correspondência, onde transmite novamente seus objetivos, citando os artistas que interessam ao projeto de indústria no Brasil. Alguns dias depois, em 9 de outubro de 1815, o cavaleiro de Brito e o marquês de Aguiar escrevem novamente à corte e passam ao rei, em português, alguns pontos da nota escrita por Le Breton. Ali, Brito considera a importância dos Ofícios em relação às Artes, ressaltando um ponto curioso a respeito da "Família Taunay", e as possibilidades de aceitação do governo perante tal proposta:

A família do pintor Taunay respeitável pelos seus costumes e reputação apurou o pequeno capital de 16 mil cruzados, e está determinada a partir antes do inverno: ela reúne um pintor, um esculptor de nome, hum chimico mettalurgico, hum farmacêutico, além de hum oficial instruído, todos de conduta exemplar. O chefe pretenderia ser professor de uma Escola de Pintura, e formar um Estabelecimento com os diversos talentos de seus filhos. Sem nada the prometer, ponderei-the unicamente que as artes liberais e de luxo deviam ceder o passo às úteis e necessárias à economia interior do Paiz, mas que o Governo de S. A. R. sendo tão iluminado, quanto protetor da industria e das artes liberais, ou lhe segurava a benevolência do meu soberano para artistas foragidos que iam buscar de tão longe seu Paternal Amparo ${ }^{18}$. tarão livres, e não se estaria em falta com o governo francês ao lhes empregar." Tradução livre do autor, Ofício n. ${ }^{\circ}$ 21,3 de outubro de 1815 , Arquivo Nacional da Torre do Tombo, Lisboa.

17. Humboldt (1811)

18. Ofício $\mathrm{n}^{\circ} 21,3$ de outubro de 1815, Arquivo Nacional da Torre do Tombo, Lisboa. 
O ofício de Brito fornece ainda uma outra pista daquela que seria a primeira idéia de uma escola de artes na cidade do Rio de Janeiro. Taunay pretendia ser professor e, ao lado dos filhos, fundar um estabelecimento voltado ao ensino da pintura. Seria o mesmo projeto de Le Breton ou havia a intenção de fundar uma escola entre a família Taunay? Pelas palavras de Le Breton no ofício anterior, há a idéia de que a família Taunay quer estabelecer-se no Brasil, associando-se a ele neste projeto voltado aos Ofícios e às artes. Ao que parece, Le Breton seria o intermediário das negociações, mas não há, ao menos nestas primeiras correspondências, qualquer intenção de permanência definitiva no Brasil por parte de Le Breton, conforme ele mesmo relata nos ofícios posteriores, que veremos adiante. Brito enfatiza a importância dos Ofícios em relação às outras artes, embora pense que a proteção será garantida pelo "iluminado" príncipe Regente .

Neste mesmo ofício, Brito respeita os talentos de Charles Simon Pradier e Grandjean de Montigny (citado neste ofício e provavelmente em outro redigido por Le Breton que não foi enviado à corte, como relata o ministro neste documento em questão), mas revela sua preferência pelos outros profissionais citados, como o "agricultor" Lelieur. Não só revela sua preferência, como afirma que, em caso de não cumprimento da oferta de pagamento das passagens dos artistas feita pelo negociante português José Alexandre Carneiro Leão, ele próprio, Brito, garantiria a viagem de Ovide e Lelieur "por julgar a sua acquisição tão necessária e preciosa". Com essa informação, temos a notícia de um possível financiamento da viagem pela burguesia portuguesa, e não pelo governo. Brito seria o financiador no caso de desistência do "negociante", demonstrando, em relação ao projeto, um interesse de cunho particular. Além da carta redigida por Le Breton, o trecho do ofício do marquês de Aguiar nos leva a considerar a hipótese de que a proposta parte dos franceses. O ministro português, mesmo considerando o projeto de Le Breton como positivo ao Brasil e tendo se empenhado perante a corte portuguesa no Brasil para a aceitação, ao menos, dos profissionais destinados aos Ofícios, afirma:

Não entro por nada na expedição projetada por Mr. Lebreton, bem que esteja certo de suas boas intenções e escolha acertada. Fico esperando as Reais Ordens para me saber regular acerca de semelhantes pretensões ${ }^{19}$.

Ainda que ofereça aos artistas a proteção de D. João VI, que certamente acolheria os artistas "foragidos", o marquês de Aguiar e o cavaleiro de Brito deixam bem claro que esperam as ordens reais para tomar qualquer iniciativa quanto ao andamento do projeto de Le Breton. A frase é enfática, embora nos faltem alguns indícios para tomar a questão como plenamente resolvida. Muitos documentos conservados nos arquivos brasileiros e portugueses ainda podem nos fornecer a chave para fecharmos a idéia do projeto de Le Breton ou mesmo nos dar mais pistas para formularmos novas hipóteses sobre essa questão. Convidados ou não, é certo que os franceses chegam ao Brasil protegidos pela corte de D. João VI. 
Em dezembro seguinte, o cavaleiro de Brito reafirma a Le Breton que não há instruções da corte para levar adiante a empresa, e que há, de fato, o desconhecimento da corte portuguesa sobre este processo de imigração que ocorre na França em direção à América, anteriormente relatado por Le Breton, dada a enorme distância em que se encontra o reino em relação ao continente europeu. Ademais, não existem fundos disponíveis para o pagamento de passagem para estes artistas se dirigirem ao Brasil, embora suas intenções, segundo Brito, sejam as melhores em relação ao progresso e desenvolvimento. Por essa razão, fora cogitada a hipótese anterior de financiamento pelo negociante português. Novamente, há a menção à proposta criada por Le Breton e dirigida aos ministros da corte portuguesa:

Vous avez aussi fait entrevoir quel'occasion était unique pour former a peu de fraix une colonie industrielle et la completer plus facilement que dans d'autres circonstances, sans blesser le Gouvernement Français, vous etiez dans l'intention d'aller vous mêmes à Rio de Janeiro offrir vos services au Gouvernement concernant cet objet important. On vous répétant toujours, Monsieur, que je manquais d'instruction à cet égard, je ne pouvais ni vous donner aucune promesse pour l'avenir, ni prendre aucun engagement qui eut l'air de préjuger les intentions de mon Gouvernement, quoique je connaisse d'ailleurs ses principes et sa politique éclairée, pour ne pas douter qu'il adoptent tous les moyens d'avancer la civilisation et la prosperité de ses vastes États, une fois que les instruments apportés de l'étranger lui fournissent une garantie de sûreté, et de bon emploi pour les faveurs qu'il voudrait leur accorder ${ }^{20}$.

Apesar da falta de instrução para resolver tal ato, o cavaleiro de Brito deixa claro que o governo poderia acolher os artistas e protegê-los no desenvolvimento de tal projeto, desde que houvesse ordens para tanto. É o que de fato acontece em março de 1816 , na chegada dos franceses ao Rio de Janeiro. Além disso, considera - e comunica a Le Breton - a importância da inclusão de artistas e literatos nacionais no caso de encaminhamento de tal projeto, uma vez que ele não poderia ser composto somente por estrangeiros. A esse respeito, Le Breton se pronuncia:

J'ai reconnu dans vos observations toute la sagesse des conversations que j'avais euts avec vous sur mon desir de faire participer le Brésil aux Beaux-Arts et à l'industrie de la France, tout ce que votre lettre renferme est marqué au coin de la Sagesse et de la Raison. J'ai été flatté de reconnaître que mes notes ne s'écarteraient point de vos principes; je n'ai proposé que des essais et non des établissements entierement etrangers et complets. Les savans en Litteratures Français sont des élemens de difficile amalgame et peut être d'une utilité très bornée dans l'étranger, ainsi n'ai-je rien proposé en ce genre. Quelques individus isolés peuvent bien servir quand la place est assigné. En projet vague ce serait une illusion. En choisissant des hommes laborieux et honnête, ayant un profession toute pratique j'ai cru servir votre Patrie et la mienne et les deux Princes qui les gouvernent ${ }^{21}$.

Convém ressaltar que Le Breton não colocaria em risco este projeto ao chamar unicamente os literatos franceses para compô-lo, pois sabe e enfatiza a Brito a dificuldade de integração destes estrudiosos. Por isso, ressalta que seu
20. "O senhor me fizera notar que a ocasião era única para formar, com poucos gastos, uma colônia industrial, e completá-la mais facilmente que em outras circunstâncias; sem ferir o Governo Francês, os senhores tinham o intento de irem, por vossa conta, ao Rio de Janeiro, oferecer vossos serviços ao governo, acerca desse objeto importante. Repetindo-vos sempre,Senhor, que me faltavam instruções a esse respeito, eu não podia nem vos dar nenhuma promessa para o futuro, nem tomar nenhuma atitude que desse a impressão de prejudicar as intenções de meu Governo, embora eu conheça, por outro lado, seus princípios e sua política iluminada, para não duvidar que eles adotem todos os meios para progredir a civilização e a prosperidade de seus vastos Estados, uma vez que os instrumentos trazidos do estrangeiro lhes forneçam uma garantia de certeza, e de bom emprego para os favores que ele gostaria de lhes conceder." Tradução livre do autor, Ofício $\mathrm{n}^{\circ} .30,9 \mathrm{de}$ dezembro de 1815, Arquivo Nacional daTorre doTombo, Lisboa.

21."Eu reconheci nas vossas observações toda a sabedoria das conversas que tive convosco, sobre o meu desejo de iniciar o Brasil nas Belas Artes e na indústria da França, tudo aquilo que vossa carta enfatiza está marcado pelo cunho da Sabedoria e da Razão. Fiquei lisonjeado em reconhecer que minhas notas não se afastariam de vossos princípios. Propus apenas ensaios e não estabelecimentos estrangeiros $\mathrm{e}$ completos. Os sábios em Literatura Francesa são elementos de difícil amálgama e talvez de uma utilidade muito limitada no 
estrangeiro, de modo que eu nunca proporia nada deste gênero. Alguns indivíduos isolados podem servir muito quando o lugar é designado. Em um projeto vago, isso seria uma ilusão. Escolhendo homens trabalhadores $\mathrm{e}$ honestos, e de profissão prática, eu acreditei servir vossa Pátria e a minha, assim como os dois Príncipes que as governam." Tradução livre do autor Ofício $\mathrm{n}^{\circ} 30,20$ de dezembro de 1815, Arquivo Nacional da Torre do Tombo, Lisboa.

22. Sobre Barca, dizAdrien Delpech:"Il avait assisté à l'ouverture du musée du Louvre, crée en 1793 sur la proposition de Sergent et de David, à la création des classes d'Architecture, de Peinture et de Sculpture, qui, constituèrent l'Institut de France ; il connaissait les chefs d'oeuvre de l'art français et les excellentes méthodes d'enseignement en honneur dans ce pays" (DELPECH, 1925, p. 127).

23. "Assim, Senhor, nesta empreitada que é toda vossa, espero que reconhecereis não vos ter dado nem promessa, nem tomado nenhuma atitude contra o meu Governo. Toca somente a ele vos conceder a acolhida hospitaleira que os talentos e a indústria têm sempre obtiveram na nossa casa, à sombra das leis sábias e paternais que tantos es trangeiros devem aben çoar por reconhecimento."Tradução livre do autor, Ofício no $30,9 \mathrm{de} \mathrm{de}-$ zembro de 1815 , Arquivo Nacional da Torre do Tombo, Lisboa projeto não tem caráter estrangeiro, indicando, conseqüentemente, a possibilidade de integração de elementos nacionais.

Finalmente, o cavaleiro de Brito aposta no projeto de Le Breton para as belas artes e os Ofícios, assim como na unidade de seu grupo, pagando, ele próprio, as despesas de viagem de Grandjean de Montigny, de Charles Simon Pradier e de suas respectivas famílias, assim como aquela de François Ovide e as feitas para o envio de algumas máquinas ao Brasil (3 moinhos). Remete as cartas necessárias ao "Ministro d'Araújo", o conde da Barca, para a apresentação do grupo de artistas e do projeto que querem levar a cabo no Rio de Janeiro. Barca seria, certamente, um aliado do grupo francês no Brasil, tendo interesse no desenvolvimento da indústria, e sendo um adepto do pensamento iluminista e profundo conhecedor do sistema de ensino artístico na França ${ }^{22}$. Ao final, deixa novamente claro a Le Breton:

Ainsi, Monsieur, dans cette entreprise qui est toute à vous, j'espère que vous reconnaîtrez ne vous avoir donné ni promesse, ni pris aucun engagement envers mon Gouvernement. C'est a lui seul à vous accorder l'accueil hospitalier que les talents et l'industrie ont toujours obtenu chez nous à l'ombre des lois sages et paternelles que tant d'étrangers doivent bénir par reconnaissance ${ }^{23}$

Le Breton encontra, portanto, o apoio de Brito para seu projeto. Este último paga não só as despesas dos artistas acima citados, mas igualmente aquela do escultor Auguste-Marie Taunay. Em carta de 20 de dezembro de 1815, Le Breton deixa transparecer a Brito que não existem ambições pessoais em seu projeto, mas sim o desejo de desenvolver as belas artes e as artes úteis num "país respeitado e promissor", além de oferecer àqueles artistas a possibilidade de trabalho e proteção fora da Europa. Pela primeira vez, revela que sua presença será útil por tempo determinado, concentrada nos primeiros meses de implantação do projeto, para o qual poderia dedicar-se até o mês de setembro de 1816 , tempo que o Institut de France Ihe proporcionaria para sua ausência.

É conveniente voltarmos, no entanto, aos escritos de Debret, presentes no início deste artigo. Humboldt e outros homens ilustres teriam influenciado Marialva nos projetos da Missão da qual Le Breton fizera parte como chefe. As palavras de Debret podem, entretanto, relacionar-se às cartas de Le Breton. Tracemos a seguinte hipótese. Mantendo boas relações com Humboldt, que era seu amigo e correspondente estrangeiro do instituto, havendo já conquistado de Le Breton o apreço às suas obras, freqüentemente citadas nas Sessões Anuais da Quarta Classe de Belas Artes do Institut de France, é novamente adequado reafirmar que Le Breton se baseou nas experiências de Humboldt pela América, ou, mesmo, que este pode tê-lo convencido das possibilidades de progresso artístico existente na América Portuguesa, tendo igualmente por base sua experiência. Ao lado disso, existe, conforme cita o próprio Le Breton, toda a questão em torno da emigração européia e as dificuldades deste processo no que tange às terras hispano-americanas. $\bigcirc$ reino português converter-se-ia em um possível berço para o progresso e para o recebimento de artistas, dada a 
difícil situação vivida pela Europa com a queda de Napoleão que, poucos anos antes, fora o responsável pela evasão da corte portuguesa para o Brasil. Ao mesmo tempo, Humboldt era o detentor das influências junto à corte portuguesa, conforme nos confirma Debret em seus escritos. Poderia ter sido Humboldt aquele a convencer o marquês de Marialva acerca de um projeto artístico e industrial no Brasil, à maneira mexicana. Este, convencido por Humboldt, pode ter articulado as primeiras correspondências entre Le Breton e Francisco José Maria de Brito, responsável pelas questões diplomáticas em Paris. Marialva, figura influente da corte portuguesa por toda a Europa, poderia dificultar o avanço das negociações em razão de suas viagens a Paris, uma vez que seu domínio diplomático se estendia por toda a Europa. Poderia, assim, ter aberto o caminho para a correspondência entre Le Breton e Brito, sabendo de possíveis intenções do governo português para o desenvolvimento industrial e artístico no Brasil, levando certamente em conta as manobras futuras do conde da Barca, iniciando as negociações do projeto. Entretanto, ainda que Marialva pensasse na aceitação de D. João Vl e no empenho do conde da Barca, confirmando todas as hipóteses anteriormente analisadas pelos historiadores brasileiros, indaga-se por que o cavaleiro de Brito não menciona nem o apoio do governo ao projeto, nem o contato com Marialva nestas últimas correspondências. Igualmente, não menciona nenhuma resposta positiva por parte da corte no Brasil. A oficialidade do projeto levaria à discussão entre Le Breton e Brito, principalmente no que se refere ao pagamento das despesas dos artistas, sem a necessidade do empenho pessoal de Brito. Finalmente, parece-nos ainda intrigante o desejo particular do cavaleiro de Brito, sendo ele um diplomata da corte portuguesa em Paris.

Na França, foram consultados os arquivos da Quarta Classe de Belas Artes, do Institut de France, no período em que Le Breton fora secretário perpétuo. Acerca das relações travadas entre Le Breton e os ministros portugueses, não foram encontradas correspondências ou documentos que as esclarecessem. Isto se deve, provavelmente, ao fato de Le Breton travar estas negociações do ponto de vista pessoal e, mais ainda, à delicada situação que vivia em Paris, em 1815, depois de discursar contra os ingleses na Sessão Anual do Instituto. Ali, Le Breton defendera com grande paixão a permanência dos objetos de arte conquistados pela França nas guerras napoleônicas, organizados por ele no Musée du Louvre, obedecendo à sua função de administrador da instituição desde 1798, assistente de Vivant Denon. Seu discurso dirige-se diretamente ao lorde Elgin e ao duque de Wellington:

En effet, pour éviter ce qui pourrait sembler nous être personnel, et nous réduisant à un seul fait, ce ne sont pas des Français qui ont arraché par lambeaux les sculptures de Phidias des monuments d'Athènes, et mis en ruine les portiques des temples violés ${ }^{24}$.

Le Breton refere-se à política de repatriação das obras de arte adquiridas por Napoleão e presentes no Louvre, como os cavalos da Basílica de San Marco em Veneza, o Apolo de Belevedère e o Laocoonte, todas estátuas trazidas da ltália, entre um número infinito de obras de arte, e apresentadas ao
24. "Com efeito, para evitar aquilo que poderia parecer ser-nos pessoal, e reduzindo-nos a um só fato, não são os franceses que arrancaram aos pedaços as esculturas de Fídias dos monumentos de Atenas, e transformaram em ruína os pórticos dos templos violados." Tradução livre da autora. $E x$ trait de Joachim Le Breton, Séance Publique de la classe des beaux-arts de l'Institut Royal de France, samedi 28 octobre 1815 , Paris, impr. F.Didot, 1815 , in- $4^{\circ}, 40-8$ p. Cf. também Goudial e Giraudon (2001, p. 474). 
25. Grandjean foi membro da Académie Royale d'Architecture e, depois de sua estadia na Académie de France em Roma, publicou com Famin, em 1815, o livro Architecture Toscane ou Palais, maisons, et autres édifices de la Toscane mesu res et dessinés. Ganhou os elogios dos acadêmicos do Instituto como grande referência ao assunto. Foi arquiteto da corte de Jérôme Bonaparte, em Cassel

26. Segundo Lebreton, Debret havia dirigido o ateliê de Jacques-Louis David por dez anos e havia sido professor de desenho no College SainteBarbe, em Paris.

27. Charles Simon Pradier e seu irmão James Pradier eram artistas suíços reconhecidos na França.

28. Nicolas-Antoine Taunay era membro da Quarta Classe de Belas Artes do Institut de France.

29.Rios Filho (1942, p. 17).

30. Ver Dias (2007). povo francês na célebre festa organizada por Le Breton e realizada no Champs de Mars, em 1798. Le Breton acusa os ingleses de terem violado os templos de Atenas, arrancando seus pórticos e suas esculturas, a partir daí subordinadas às coleções do British Museum, como parte da política inglesa durante a investida contra Napoleão e recuperação do poderio inglês na Europa. As frases de Le Breton surtiram, evidentemente, grande efeito. No ano seguinte, ele parte para - Brasil, como chefe de uma colônia de artistas, levando adiante o projeto apresentado ao cavaleiro de Brito e ao marquês de Aguiar. Já não poderia mais voltar a Paris no mês de setembro de 1816, conforme dissera a Brito em suas últimas correspondências. Estava excluído do Instituto como secretário perpétuo e membro da Quarta Classe de Belas Artes e Literatura Antiga, conseqüência evidente de sua posição contra a política de repatriação das obras de arte e divergência com os ingleses.

Junto a Le Breton, chefe dos artistas, integravam o grupo o arquiteto Grandjean de Montignyy ${ }^{25}$, o pintor de historia Jean-Baptiste Debret ${ }^{26}$, o gravador suíço Charles Simon Pradier ${ }^{27}$ e o pintor de paisagem Nicolas-Antoine Taunay ${ }^{28}$, entre outros. Ao lado dos artistas, juntava-se um grupo de artesãos que comporia a parte dos Ofícios da futura instituição, entre os quais "o mestre serralheiro Nicolas Magliori Enout, o mesmo ferreiro e perito em construção naval JeanBaptiste Level, e os surradores de peles e curtidores Fabre e Pilité" 29 , e François Ovide, que fizera parte do grupo financiado por Brito.

A partir daí, é-nos mais conhecida a história que se segue. $\bigcirc$ projeto de Le Breton resulta, dez anos depois, na fundação da Academia Imperial de Belas Artes, sem a parte relativa aos ofícios ${ }^{30}$. Apesar de todas as evidências se dirigirem à criação do projeto por parte de Le Breton, suas relações com Humboldt, os contatos estabelecidos com os diplomatas portugueses na Europa e sua aceitação pela corte portuguesa, culminando na efetiva proteção dada pelo rei D. João VI no Brasil, em 1816, resta-nos ainda debruçarmo-nos sobre o restante da documentação conservada na Torre do Tombo. Novos caminhos, portanto, na busca pela compreensão definitiva desta Missão.

\section{REFERÊNCIAS}

ANTIGUO COLEGIO DE SAN ILDEFONSO (México). Alejandro de Humboldt. Una Nueva Vision del Mundo. Catálogo. México: UNAM, 2003

BARATA, Mário. Manuscrito inédito de Lebreton. Sobre o estabelecimento de dupla escola de artes no Rio de Janeiro, em 1816. Revista do SPHAN, Rio de Janeiro. n. 14, p. 283-307, 1959.

DEBRET, Jean-Baptiste. Viagem pitoresca e bistórica ao Brasil. São Paulo: Martins; Brasília: INL, 1975.

DELPECH, Adrien. Une mission artistique au Brésil. La mission française de 1816. Revue de l'Amerique Latine, Paris, t. IX, n. 37, jan. 1925. 
DIAS, Elaine. Les artistes français au Brésil au XIXe sciècle: l'Académie des Baux-Arts et la formation de la collection nationale de peintures de Rio de Janeiro. In: PRETI-HAMARD, Monica; PANZANELLI, Roberta (orgs.). La circulation des oevres d'art. The circulation of works of art in the Revolution Era 1789-1848. Rennes: Presses Universitaires de Rennes, 2007 (no prelo).

DUQUE-ESTRADA, Gonzaga. Arte Brasileira. Campinas: Mercado das Letras, 1995.

GOUDAIL, Agnes; GIRAUDON, Catherine. Procès-verbaux de l'Académie des Beaux-Arts. Tome premier: 1811-1815. Paris: Honoré Champion, 2001.

HUMBOLDT,Alexander von. Essai politique sur le Royaume de la Nouvelle Espagne. Paris: F. Schoell, 1811, 5v.

JOUIN, Henry.Joachim Lebreton. Premier secrétaire perpétuel de l'Académie des Beaux-arts. Paris:Aux Bureaux de l'Artiste, 1892.

LEBEN, Ulrich. École Royale Gratuite de Dessin de Paris, 1767-1815. Saint-Rémy-en-l'Eau: Monelle Hayot, 2004.

MANTZ, Paul. L'enseignement des arts industriels avant la révolution. Gazette des Beaux-Arts, Paris, p. 229-245, mars, 1865.

RIOS FILHO,Adolfo Morales de los. O ensino artístico. Subsídio para a sua Historia. Um capítulo 1816-1889. Rio de Janeiro: Imprensa Nacional, 1942.

NAVES, Rodrigo. A forma difícil. São Paulo: Ática, 1996.

PEDROSA, Mário. Obras completas de Mário Pedrosa. v. X. São Paulo: Editora, 1955. .Acadêmicos e modernos. Textos Escolhidos III. São Paulo: Edusp, 1998.

TAUNAY,Affonso d'E. A Missão Artística de 1816. Rio de Janeiro: Patrimônio Histórico e Artístico Nacional, 1957.

Artigo apresentado em 8/2006. Aprovado em 9/2006. 